Check for updates

Cite this: RSC Adv., 2018, 8, 21174

\title{
Chiral ionic liquids supported on natural sporopollenin microcapsules $\uparrow$
}

\author{
Ivan Palazzo, ${ }^{a}$ Andrea Mezzetta, ${ }^{a}$ Lorenzo Guazzelli, (DD *a Stefania Sartini, ${ }^{a}$ \\ Christian Silvio Pomelli, ${ }^{a}$ Wallace O. Parker Jr ${ }^{\mathrm{b}}$ and Cinzia Chiappe (DD *a
}

Supported chiral ionic liquids (SILS) were prepared choosing the starting material for the ionic liquid part from the enantiopure stock of the chiral pool (monoterpenoids and an amino acid) and the sporopollenin as an environmentally friendly support. Sporopollenins are microcapsules with naturally well-defined sizes and shapes that can be obtained from pollen grains after removal of the internal cytoplasm and the second shell layer. As thermally stable organic biocompatible structures, sporopollenins have attracted increasing interest in recent years for several applications. Herein, biobased ILs were anchored onto the surface of sporopollenins obtained from the pollen of Populus deltoides, selected as a model pollen grain. These new structures, which present an external positively charged shell, were characterized by physico-chemical techniques (ATR-FTIR, TGA, SEM, EDX, and solidstate ${ }^{13} \mathrm{C}$ NMR). A metathesis reaction was also performed on selected bio-based IL modified sporopollenins, demonstrating the possibility to switch the surface properties by exploiting well-known IL chemistry.

Received 22nd April 2018 Accepted 31st May 2018

DOI: $10.1039 / \mathrm{c} 8 \mathrm{ra0} 3455 \mathrm{a}$

rsc.li/rsc-advances science and material chemistry, SILs can modify and improve the properties of solids, modifying wettability, lubricating properties, separation efficiency and electrochemical response. ${ }^{12}$ To date, zeolite-, silica-, carbon nanotube-, polystyrene- and cross-linked polymers represent the most used materials to obtain SILs. However, many of these IL supports possess some disadvantages: complicated preparation technologies and a high production costs are required, in particular, when empty size homogeneous systems with peculiar microscale and nanoscale architectures are mandatory. Thus, the possibility to have highly effective and cheap polymeric supports for the heterogeneous catalysts is high desirable. Nature can provide a myriad of unique, widely available biological materials with surprising microscale and nanoscale architectures. One interesting natural alternative to synthetic organic polymers is represented by sporopollenin, a highly cross-linked polymer, which is the main component of outer shell of pollen grains and plant spores (exine). ${ }^{13}$ It is characterized by a remarkable chemical, physical and biological stability even at high temperatures, that arise from its high cross-linked structure involving tertiary carbons and ethers. Although it is still a matter of discussion, ${ }^{\mathbf{1 4 - 2 1}}$ sporopollenin possesses aliphatic chains bound to aromatic moieties, conjugated phenols, aliphatic alcohols, lactones, and carboxylic acids. Morphologically, sporopollenin exine capsules (SEC) are microcapsules with a hydrophobic cavity and a variable number of pores, species specific in shape and size, with elaborated 3D surface architectures. SEC have been used to sequester edible oils from emulsions efficiently, encapsulate various polar and
${ }^{a}$ Dipartimento di Farmacia, Università di Pisa, Via Bonanno 33, 56126, Pisa, Italy. E-mail: cinzia.chiappe@unipi.it; lorenzo.guazzelli@unipi.it

${ }^{b}$ Eni, Research \& Technical Innovation, Physical Chemistry Department, Via Maritano 26, San Donato Milanese, 20097, Italy

$\dagger$ Electronic supplementary information (ESI) available. See DOI: 10.1039/c8ra03455a 
nonpolar materials, and act as drug delivery systems with excellent enhanced bioavailability. ${ }^{22-27}$ On the other hand, the presence of functional groups on the outer surface allows for their further modification. Chemically modified SEC have been employed in water remediation studies, ${ }^{28}$ as stationary phases chromatography, ${ }^{29}$ and as solid supports for peptide synthesis, ${ }^{30}$ enzyme immobilization,,$^{31,32}$ and chemical reactions. ${ }^{33,34}$ In the context of drug delivery, efficient drug encapsulation systems have also been prepared by coating SEC with natural biopolymer composites. ${ }^{35,36}$ Recently, sporopollenin has also been used in the area of biomass valorization. SEC surfaces have been modified by sulfonation, and the obtained material tested as a heterogeneous catalyst in the dehydration of D-xylose and xylan to produce furfural. ${ }^{37}$

Despite its potentiality also the chemistry of SEC presents some drawbacks in term of sustainability. Extraction of SEC from the whole pollen grains and plant spores traditionally entails the use of harsh working protocols/conditions (e.g. acetic anhydride/ sulfuric acid and heating, ${ }^{38} \mathrm{HF},{ }^{39} 4$-methylmorpholine $\mathrm{N}$-oxide, ${ }^{40}$ $\mathrm{KOH} / \mathrm{H}_{3} \mathrm{PO}_{4}$ (ref. 41)). Moreover, these procedures, which are necessary to remove the internal cytoplasm and the second shell layer (intine), comprised mainly of cellulose, hemicellulose, and pectin, can determine significant modifications on the polymer composition and capsule shape, negatively affecting their use in a variety of the above mentioned applications.

However, an improvement to SEC extraction, in terms of time and environmental impact, has been proposed by Mundargi et $a .^{42}$ and, more recently, the possibility to use ILs as extraction media has been demonstrated by Chiappe et al., although the product was not fully characterized or explored as polymeric support. $^{43}$

Herein we show that sporopollenin microcapsules, purified using an IL, can be used to prepare, through grafting procedures, charged natural polymeric capsules. Despite the increasing number of studies aimed at using SEC as solid supports, surprisingly, these microcapsules have never been employed for the immobilization of ILs. The excellent stability and durability of the employed materials and the tunability of anchored ILs, which are also chiral, give the possibility to obtain new environmentally friendly functional materials with high potentialities for application in catalytic reactions, separation technologies and electrochemistry.

\section{Results and discussion}

Sporopollenin exine capsules (SEC) were isolated from defatted pollen of Populus deltoides using the recently reported extraction protocol based on acidic ILs. ${ }^{\mathbf{4 3}}$ Briefly, pollen grains were suspended in 1-(4-sulfobutyl)-3-methylimidazolium hydrogen sulfate, $\left[\mathrm{HSO}_{3} \mathrm{C}_{4} \mathrm{mim}\right]\left[\mathrm{HSO}_{4}\right]$, and heated to $160{ }^{\circ} \mathrm{C}$ for 90 minutes. The ATR-FTIR spectrum of the isolated SEC (Fig. 1) is in agreement with those reported previously. Comparison with the spectrum of the pristine pollen clearly shows the removal of the polysaccharide portion (absence of the strong $\mathrm{C}-\mathrm{O}-\mathrm{C}$ and $\mathrm{C}-$ $\mathrm{OH}$ stretching at $1047 \mathrm{~cm}^{-1}$ ), of the protein component (absence of the amide II band at $1544 \mathrm{~cm}^{-1}$ ), and of the lipid fraction (absence of signals at $1738 \mathrm{~cm}^{-1}$ and $1408 \mathrm{~cm}^{-1}$ ). These

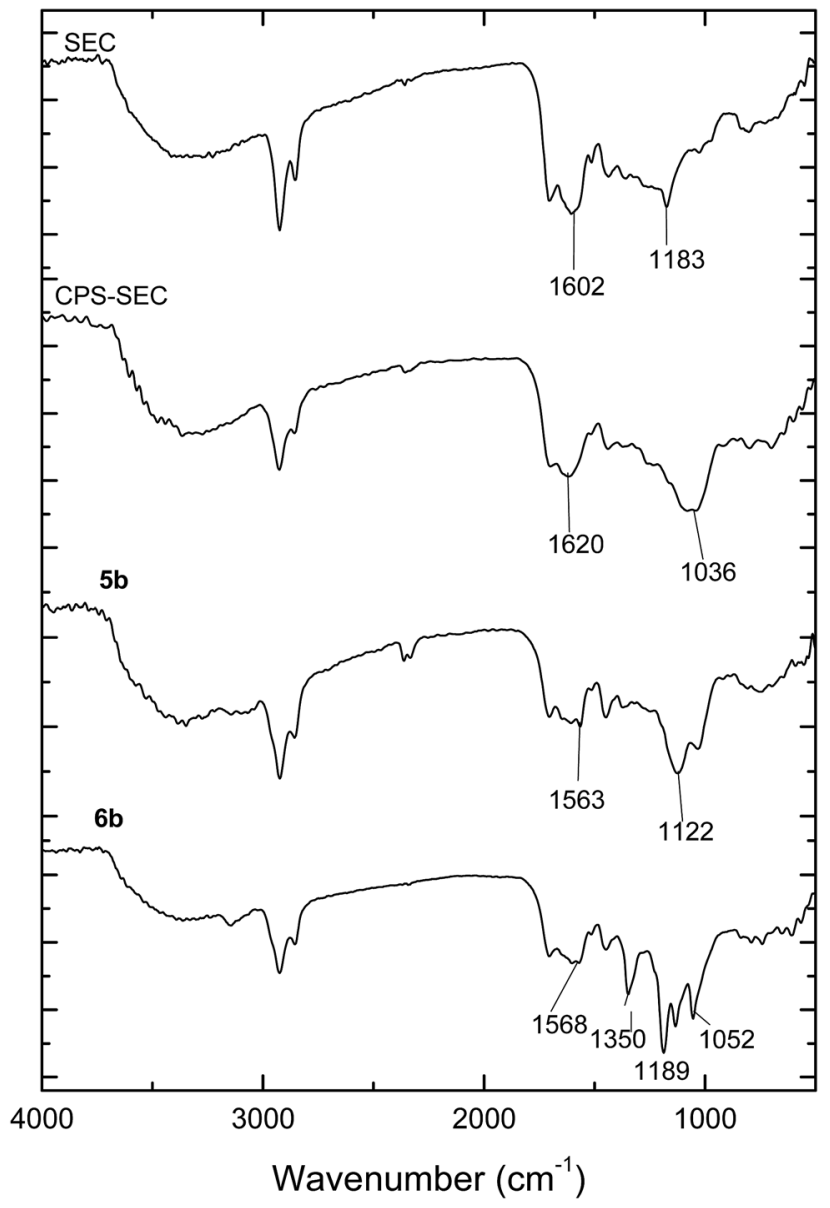

Fig. 1 ATR-FTIR spectra of sporopollenin (SEC), 3-chloropropylfunctionalized sporopollenin CPS-SEC and IL-functionalized sporopollenins: $5 b$ and $6 b$.

data confirm that the treatment with $\left[\mathrm{HSO}_{3} \mathrm{C}_{4} \mathrm{mim}\right]\left[\mathrm{HSO}_{4}\right]$ can be considered an adequate chemical protocol to eliminate all the undesired components, including also proteins that may cause potential allergic reactions. However, as previously observed, ${ }^{43}$ the main peculiarity of the FTIR spectrum of these SEC was the presence of two peaks at $1183 \mathrm{~cm}^{-1}$ and $1036 \mathrm{~cm}^{-1}$, which are usually not detected. Such signals can be assigned to the $\mathrm{O}=\mathrm{S}=\mathrm{O}$ group stretching modes. In agreement, elemental analysis showed the presence of sulfur in isolated SEC which was confirmed also by the EDX analysis. Although, in principle, these bands could be related to the presence of residual IL, having the $\mathrm{SO}_{3} \mathrm{H}$ group on the cation and hydrogen sulphate as the anion, their persistence also after extensive washing with ethanol, methanol, toluene, and water strongly suggested the presence of a covalent linkage. Previously, we hypothesized ${ }^{\mathbf{4 3}}$ the transformation of the hydroxyl groups on sporopollenin into the corresponding sulphate monoesters, through a process probably catalyzed by the acidic IL. This supposition finds a further support in the fact that the FTIR spectrum of a sulfonated sporopollenin, recently prepared by treating sporopollenin with chlorosulfonic acid, ${ }^{37}$ turns out to be very similar to the spectrum presented in this work, the two aforementioned peaks being present in both spectra. 


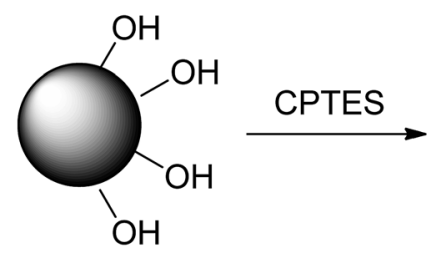

SEC

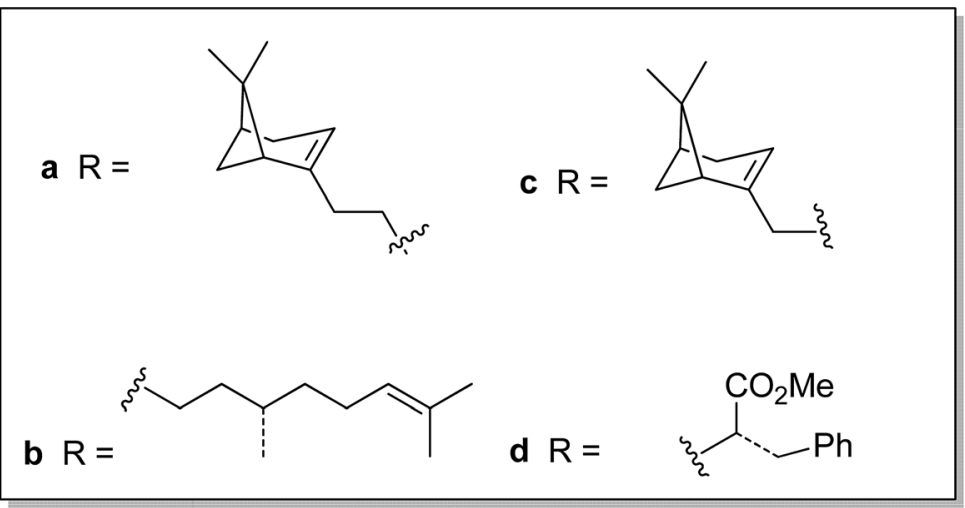

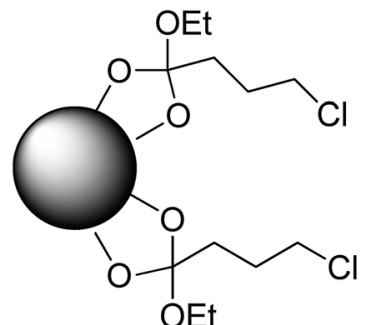

CPS-SEC
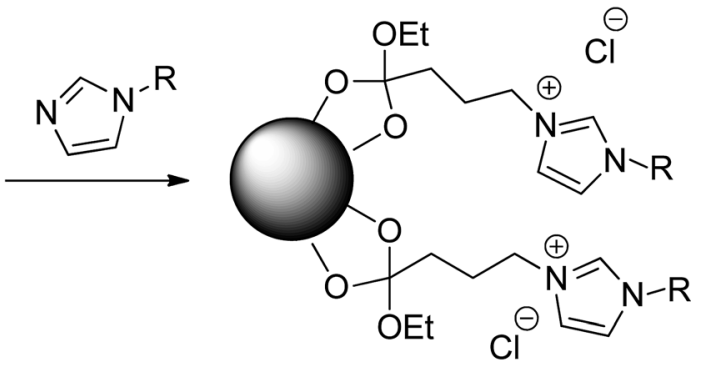

$5 a-d$<smiles>[14CH3]N[14CH3]</smiles><smiles>[R]n1cc[n+](CCCC2(OCC)O[C@H]3CCCC[C@@H]4O[C@](CCC[n+]5ccn([R])c5)(O[C@@H]34)O2)c1</smiles>

$6 b, 6 d$

Scheme 1 Preparation of ILs functionalized SEC.

Although this functionalization could negatively affect the subsequent functionalization reactions, fortunately, the treatment of the isolated SEC with a solution of (3-chloropropyl) triethoxysilane (CPTES), following a procedure similar to that recently reported in the literature ${ }^{44}$ gave the desired Sifunctionalized sporopollenin, CPS-SEC. CPS-SEC were further transformed into IL-modified sporopollenin capsules (5a-d) by reaction with four different 1-alkylimidazoles (4a-d), Scheme 1.

In particular, three natural alcohols, namely (-)-nopol (1a), $(S)-(-)-\beta$-citronellol (1b) and (-)-myrtenol (1c), which are also chiral, were used as starting materials to synthesize the respective 1-alkylimidazoles in a two step process. (-)-Nopol and $(S)-(-)-\beta$-citronellol were transformed, in very high yields, into the corresponding mesylates $(\mathbf{2} \mathbf{a}-\mathbf{b})$ by reaction with methanesulfonyl chloride, in the presence of $\mathrm{Et}_{3} \mathrm{~N}$, and the isolated compounds $\mathbf{2 a - b}$ were reacted with an equimolar amount of sodium imidazolate. Interestingly, when the same approach was performed on (-)-myrtenol, only the corresponding allyl chloride (3c) was isolated in good yield. This probably arises from the displacement by the chloride of the first formed mesylate. Reaction of $3 \mathbf{c}$ with sodium imidazolate gave the expected product (4c) in good yield (Scheme 2).

Chiral imidazole 4d was obtained instead starting from Lphenylalanine, glyoxal, formaldehyde, and ammonia through the Debus-Radziszewski reaction. ${ }^{45}$ The desired product $4 \mathbf{d}$ was isolated in $48 \%$ yield, in agreement with the literature. ${ }^{45}$

To provide new properties to the IL-modified SEC, an anion metathesis aimed at substituting the chloride anion with the bis(trifluoromethylsulfonyl)imide anion was performed on compounds $5 \mathbf{a}$ and $\mathbf{5 d}$. This kind of anion metathesis is usually performed to prepare highly hydrophobic ionic liquids. Likewise, the presence of this heavily fluorinated anion could determine the hydrophilic-hydrophobic switch of the sporopollenin surface, contemporaneously, increasing the thermal stability of the resulting material. The well-known tunability of ILs can become an efficient method to modify the whole sporopollenin surface. The reaction was carried out by suspending the IL-functionalized sporopollenin in an aqueous solution of $\operatorname{LiTf}_{2} \mathrm{~N}$ and stirring the mixture at room temperature for 48 hours, to give derivatives $\mathbf{6 b}$ and $\mathbf{6 d}$ (Scheme 1).

IL modified sporopollenins $\mathbf{5 a}-\mathbf{d}$, the related $\mathrm{Tf}_{2} \mathrm{~N}$ derivatives, and their precursors were characterized by means of ATRFTIR, SEM, EDX, solid-state ${ }^{13} \mathrm{C}$ NMR analyses and TGA.

ATR-FTIR analysis and focal plane array imaging of the ILfunctionalized SEC

Pollen grains and their modified forms were initially characterized by ATR-FTIR. The spectrum of CPTES immobilized sporopollenin CPS-SEC (Fig. 1) shows the characteristic adsorption band of the Si-O stretching at $1036 \mathrm{~cm}^{-1}$, demonstrating that the modification was successful. In Fig. 1 are also reported the IR spectra of the sporopollenin derived from the treatment with $\left[\mathrm{C}_{4} \mathrm{mimSO}_{3} \mathrm{H}\right]\left[\mathrm{HSO}_{4}\right](\mathrm{SEC})$ and the $(S)-(-)-\beta$ citronellol IL-functionalized sporopollenin both with $\mathrm{Cl}^{-}$and $\mathrm{Tf}_{2} \mathrm{~N}^{-}$counterions, as examples of bio-based supported derivatives. These latter, although very similar to the CPS-SEC 

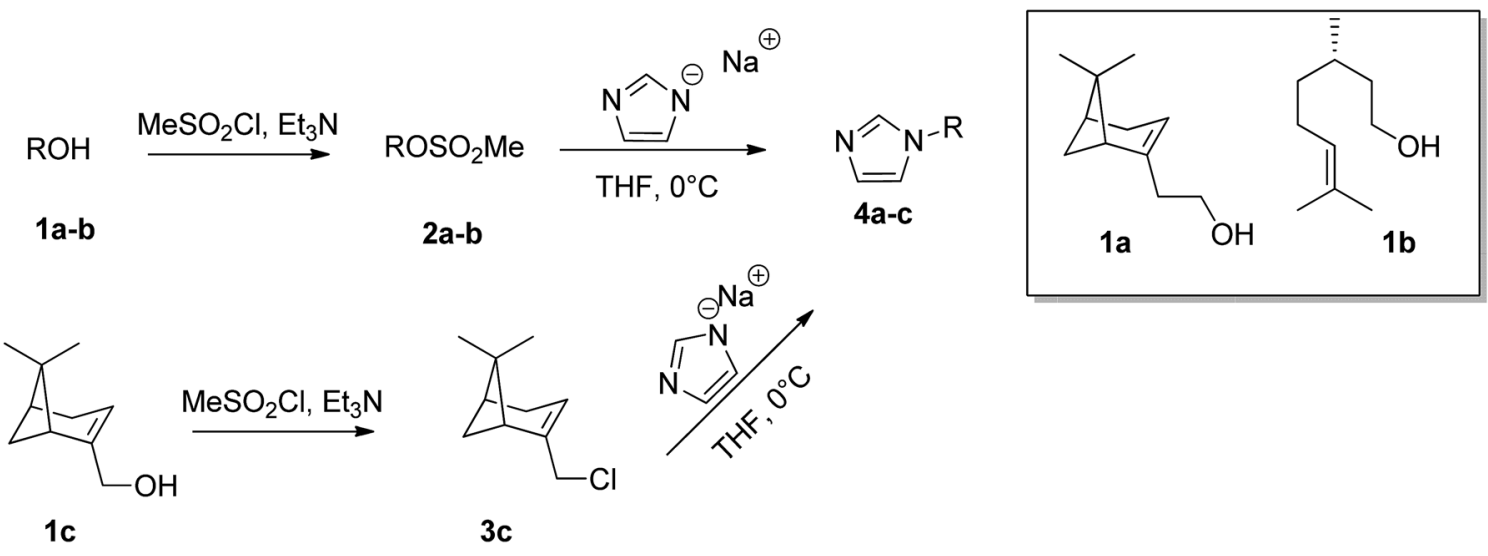

Scheme 2 Preparation of alkylimidazoles.

spectrum, show the distinctive absorption bands of the imidazolium moiety (around $1600 \mathrm{~cm}^{-1}$ and between $1109 \mathrm{~cm}^{-1}$ and $1132 \mathrm{~cm}^{-1}$ ). On the other hand, after anion exchange the typical strong absorption of $\mathrm{CF}_{3}$ and $\mathrm{SO}_{2}$ can be evidenced (asymmetric stretching of $\mathrm{CF}_{3}$, around $1200^{-1}$, asymmetric and symmetric stretching of $\mathrm{SO}_{2}$, around 1350 and $1190-1130 \mathrm{~cm}^{-1}$, respectively). It is noteworthy that, although these bands in the case of free ILs often show the most pronounced dependence on the state of salt (liquid-solid) and $\mathrm{CF}_{3}$ and $\mathrm{SO}_{2}$ are the principal moieties involved in the cation and anion interactions, in this case moderate (if any) changes have been observed with respect to analogous not supported ILs, based on 1-alkyl-3methylimidazolium cations. This suggest that, as desired, the grafting of the IL on the SEC surface is not accompanied by strong interactions between IL and support: thus, the IL should largely maintain their peculiar physico-chemical features.

For selected sporopollenin samples, false-colour images were obtained using the Focal Plane Array (FPA) imaging technique, as shown in Fig. 2. For each sample, a real-colour optical image was first collected to select the area for imaging. Subsequently, after the FTIR spectra of the sample were recorded for each pixel, a wavenumber was selected in order to obtain information about the spatial distribution of specific chemical components on the micro-capsules. The colours of the pixels span from red to blue, passing through orange, yellow, green, and light blue, indicating an increasing absorbance on that pixel at the specified wavenumber. Fig. 2 illustrates visible and FPA images of 3chloropropyl-functionalized sporopollenin CPS-SEC, and IL-
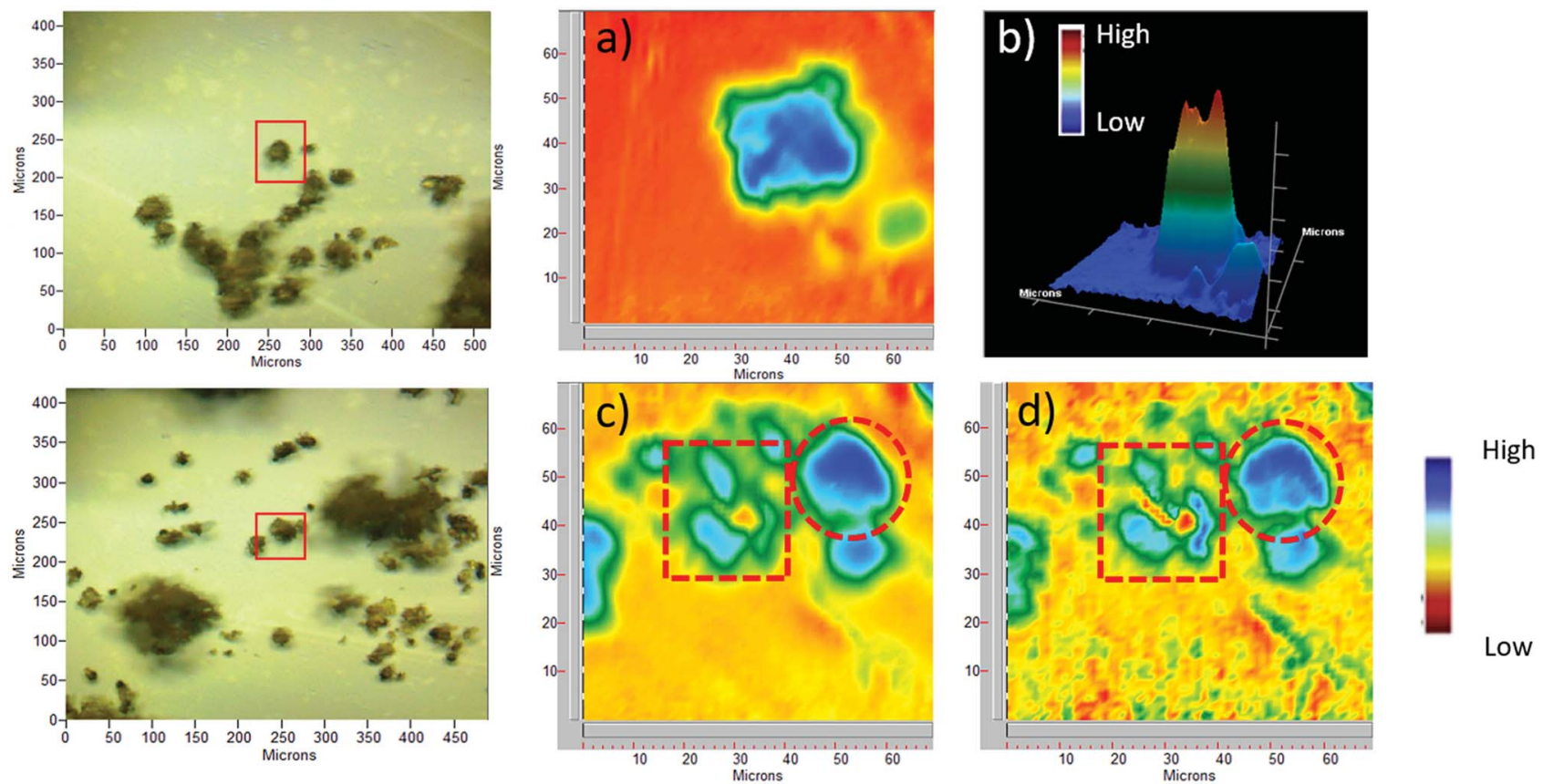

Fig. 2 Optical and FPA images: (a) 2D image (blue is high) of 3-chloropropyl-functionalized sporopollenin CPS-SEC, selected wavenumber $1035 \mathrm{~cm}^{-1}$; (b) 3D image (red is high) of CPS-SEC; (c) 2D image of IL-functionalized sporopollenin $5 \mathrm{~b}$ at $1035 \mathrm{~cm}^{-1}$; (d) $2 \mathrm{D}$ Image of $5 \mathrm{~b}$ at $1563 \mathrm{~cm}^{-1}$. Red circles indicate intact pollen grains, whereas red squares show pollen fragments. 


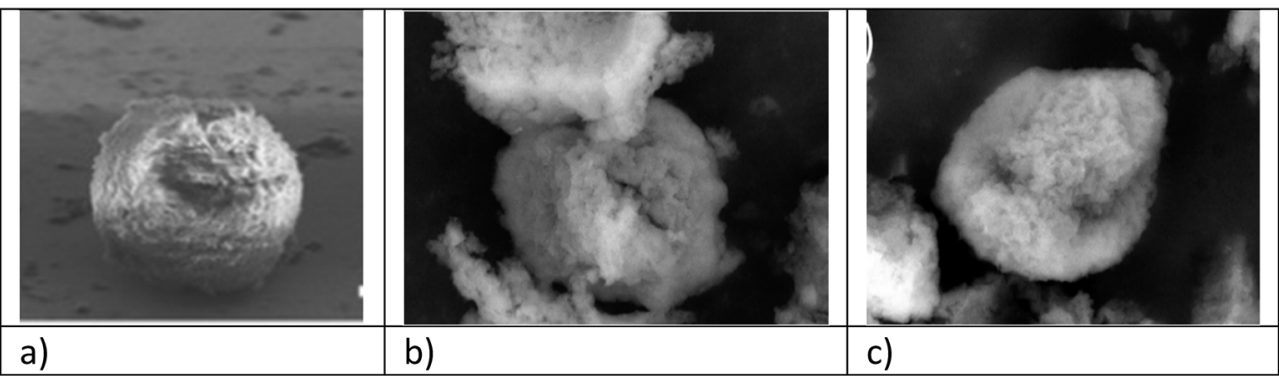

Fig. $3 \mathrm{SEM}$ images of (a) sporopollenin extracted with the IL $\left[\mathrm{HSO}_{3} \mathrm{C}_{4} \mathrm{mim}\right]\left[\mathrm{HSO}{ }_{4}\right]$, (b) 3-chloropropyl-functionalized sporopollenin CPS-SEC and (c) IL-functionalized sporopollenin $5 \mathrm{~b}$.

functionalized sporopollenin, respectively. Data referred to pollen grains treated with $\left[\mathrm{C}_{4} \mathrm{mimSO}_{3} \mathrm{H}\right]\left[\mathrm{HSO}_{4}\right]$ are not shown as they are in good agreement with results obtained in our previous work. ${ }^{43}$ The blue colour distribution in the FPA images of Fig. $2 \mathrm{a}$ and $\mathrm{b}(2 \mathrm{D}$ and $3 \mathrm{D}$ images, respectively), related to CPS-SEC sample, confirms not only that Si-derivatization has been carried with success but also that $\mathrm{Si}$ is well-distributed on the SEC surface. In this case, the wavenumber selected is $1035 \mathrm{~cm}^{-1}$, which is the characteristic band of $\mathrm{Si}-\mathrm{O}$ bond stretching mode. In the lower row of Fig. 3, the optical image of CPS-SEC functionalized with $(S)-(-)-\beta$-citronellol $\mathbf{C l}$ ionic liquid, sporopollenin $\mathbf{5 b}$, is shown on the left. On the right, is the false-colour image at two selected wavenumbers. In Fig. 2c, the wavenumber is $1035 \mathrm{~cm}^{-1}$ corresponding to silanyl moieties, corroborating the fact that $\mathrm{Si}^{-}$ O groups are always well distributed, while in Fig. 3d the referring band is $1563 \mathrm{~cm}^{-1}$, typical of imidazolium-based compounds. As seen from the false colour image, blue-green is also in this case quite well distributed on the surface of the analyzed sample, revealing an efficient functionalization of sporopollenin with chiral bio-based ionic liquid.

\section{SEM imaging and energy-dispersive X-ray (EDX) spectroscopy of the IL-functionalized SEC}

In order to observe their morphology, SEM images were collected for the sporopollenin samples (Fig. 3). The sporopollenins capsule obtained after treatment with the acidic ionic liquid $\left[\mathrm{HSO}_{3} \mathrm{C}_{4} \mathrm{mim}\right]\left[\mathrm{HSO}_{4}\right]$ is shown in panel a. The characteristic microstructure of the exine surface is partially lost after the treatment; moreover, the diameter of the capsule decreases slightly due to the removal of the intine layer and the interior protoplast. However, the circular shape is still well recognizable. Panel b illustrates a SEM image of the 3-chloropropylmodified sporopollenin CPS-SEC, in which the presence on the sporopollenin capsule of an additional external layer can be observed, as well as the presence of some minor fragments on the capsule surface. Finally, panel c represents ILfunctionalized sporopollenin $\mathbf{5 b}$. As observed for all the other bio-based IL-functionalized sporopollenin synthesized (ESI $\dagger$ ), the SEM image is similar to that of CPS-SEC, showing that the last reaction, IL grafting, has only a very few (if any) effect on capsule size and morphology.

Finally, to detect elements not revealed by elemental analysis EDX microanalyses were performed on some of the sporopollenin samples (Fig. S3†). As expected, the spectrum of the pristine pollen shows a large variety of elements apart from carbon, nitrogen, oxygen, and sulphur. In particular, sodium, magnesium, phosphorus, potassium, iron, and lead were also detected. All these elements disappear in the EDX spectrum of the 3-chloropropyl-functionalized sporopollenin CPS-SEC, whereas silicon and chlorine are clearly visible. According to this analysis, the silicon concentration turns out to be around $0.58 \mathrm{mmol}$ per gram of CPS-SEC. Among the IL-modified sporopollenin materials, $\mathbf{5 a}$ and $\mathbf{5 b}$ were chosen to perform the EDX microanalysis. The spectra show the presence of carbon, nitrogen, oxygen, sulphur, silicon, and chlorine as the most abundant elements. In particular, the ratio between $\mathrm{Si} / \mathrm{N}$ changes in these latter samples in accordance with the IL functionalization.

\section{Solid-state ${ }^{13} \mathrm{C}$ NMR analyses}

IL-functionalized sporopollenin 5a was examined also by ${ }^{13} \mathrm{C}$ CP-MAS NMR spectroscopy. The spectrum obtained with $12 \mathrm{kHz}$ sample rotation (Fig. 4) shows no appreciable spinning sidebands (95 ppm intervals), as verified by spinning at $8 \mathrm{kHz}$ (see ESI Fig. S1 $\dagger$ ), indicating that the organic species giving the most intense peaks are not rigid solids. Several resolved peaks $(10,38$, 41, 46, 122 ppm) correspond to those expected for $\mathbf{5 a}$ (Fig. S2 $\dagger$ ) can be indeed easily evidenced. However, there are also some extra species giving signals near 70 and 100 ppm (C-O), $150 \mathrm{ppm}$ (oxygenated aromatics), $170 \mathrm{ppm}$ (carboxylate) and $200 \mathrm{ppm}$ (ketones), attributable to the SEC support.

The largest signal at $30 \mathrm{ppm}$, due to aliphatic carbons, was also observed for SEC, along with the sharp signal at $129 \mathrm{ppm}$. Sporopollenins contain aromatic (129 ppm) and aliphatic (30 $\mathrm{ppm}$ ) carbons thought to originate from the phenylpropanoid pathway and from waxes of the exine ${ }^{46}$ These two ${ }^{13} \mathrm{C}$ signals have surprisingly short longitudinal relaxation times, being well evidenced even with re-cycle delays of only $0.3 \mathrm{~s}$ (Fig. S1†). Clearly, the carbon nuclei giving these signals are near paramagnetic sites (unpaired electrons). The paramagnetic properties of these materials, which will be more in detail examined in the future, could be of interest for specific applications, for instance for the development of bio-inspired paramagnetic particle labels to be used in magneto immunoassay, as well as for a more generic antioxidant activity. 


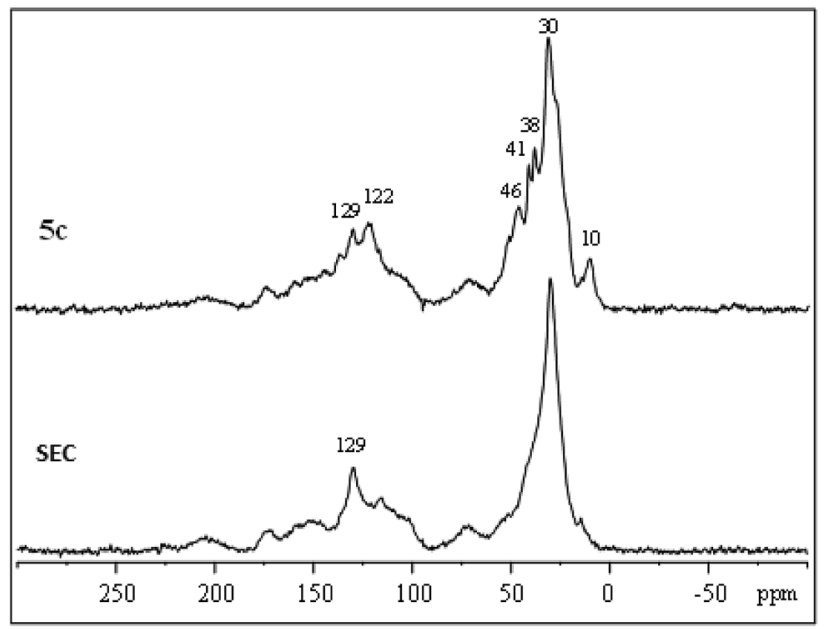

Fig. $4{ }^{13} \mathrm{C}$ CP-MAS NMR spectrum of sporopollenin (SEC) and ILfunctionalized sporopollenin $5 a$.

\section{Thermogravimetric analyses of IL-functionalized SEC}

Finally, functionalized and non-functionalized sporopollenin microcapsules were also characterized by thermal gravimetric analysis, under nitrogen. Since it is well-known that temperature ramp in TGA measurements causes mass loss resulting from either thermal decomposition or evaporation of ILs and the temperature profile depends on some operating factors, such as heating rate, instrumentation, type of carrier gas, and sample amount, measurements were carried out under identical conditions. The maximum thermal degradation temperature of sporopollenin arising from IL treatment was recorded at $431{ }^{\circ} \mathrm{C}$ (Fig. S4 $\dagger$ ), in agreement with the high thermal stability of this biopolymer. It is worth noting the presence of a small shoulder at around $250{ }^{\circ} \mathrm{C}$ on the DTG plot that can be attributed to a first partial degradation, due to oxygen release. On the other hand, TGA of lightly washed sporopollenin, containing residual acidic IL, gave a well-distinguishable additional peak at about $200{ }^{\circ} \mathrm{C}$, which disappeared after refluxing the sporopollenin in methanol (data not shown). The CPTES-modified sporopollenin showed a similar trend to the washed sporopollenin, with the principal peaks shifted toward higher temperatures $\left(451{ }^{\circ} \mathrm{C}\right)$. Furthermore, the total weight loss was about $5 \%$ less for the modified sporopollenin than the unmodified one (Fig. 5a). This is probably due to the presence of silica atoms in the former. The thermogram of the IL-modified sporopollenin 5b presents two new peaks at $208{ }^{\circ} \mathrm{C}$ and $291{ }^{\circ} \mathrm{C}$, which can be attributed to the degradation of the grafted IL moiety (Fig. 5b), whereas the maximum thermal degradation occurs at $448{ }^{\circ} \mathrm{C}$, i.e. at a temperature which is close to the value of the unmodified sporopollenin. Interestingly, the degradation profile of the IL-modified sporopollenin $\mathbf{6 b}$ (Fig. 5b) shows instead only a small degradation peak at $204{ }^{\circ} \mathrm{C}(<5 \%)$, it principally decomposes at $437{ }^{\circ} \mathrm{C}$. As expected, the thermal stability of the sporopollenin supported ionic liquids depends on counter anion: analogously to the situation characterizing free ILs, a significant thermal stability increase has been observed changing the anion from chloride to $\mathrm{Tf}_{2} \mathrm{~N}$. Still, this thermal stability is very high for an IL supported on capsules with biological origin and it is a desirable property for a carrier to be used in wide range of temperatures.

\section{Conclusions}

We believe that our approach, based on simple reactions, can provide new smart 3D-microcapsules exploiting the unique properties of pollen grains and tailor-made ionic liquids.

Treatment with $\left[\mathrm{C}_{4} \mathrm{mimSO}_{3} \mathrm{H}\right]\left[\mathrm{HSO}_{4}\right]$ allows to obtain easily sporopollenin capsules through an efficient removal of the other components, mainly cellulose and proteins.

SEM images show that, both after the first treatment and the following ones, the sporopollenin retained its distinctive spherical shape and collapse phenomena having detrimental effects on absorption/release mechanisms, generally observed when harsh purification procedures are used, are largely avoided.

ATR-FTIR/focal plane array imaging and SEM/EDX analyses show that Si and ILs are well distributed on the capsule surface.

Solid-state ${ }^{13} \mathrm{C}$ NMR suggests interesting paramagnetic properties of these materials.

Finally, thermal analyses of IL decorated sporopollenin capsules evidence a high stability of these materials, which depend largely on IL anion. The degradation profile of the ILmodified sporopollenin $\mathbf{6 b}$ shows indeed only a small degradation peak at $204{ }^{\circ} \mathrm{C}(<5 \%)$, it principally decomposes at $437^{\circ} \mathrm{C}$.

To the best of our knowledge, this is the first example of sporopollenin capsules decorated with positively charged moieties. Normally, sporopollenin possess ionisable groups on their surface that become increasingly negatively charged with an increase in $\mathrm{pH}^{47}$ The presence of positive charges could instead facilitate the adhesion of these materials to negativelycharged surfaces, such as negatively charged synthetic materials or the cell membranes of a range of bacteria.

Nonetheless, the obtained thermal stable bio-based IL-SEC hybrid structures may lead to improved systems for many of the fields mentioned in the introduction and may clear the way for the development of new applications. For instance, surface modification of sporopollenin has recently allowed for the development of micromotors able to transport bovine serum albumin loaded into the microcavity. ${ }^{48}$ The proposed modification, which also permit the tuning of the hydrophobic/ hydrophilic surface properties by means of the metathesis reaction, could further boost research into this direction, with an extra option of target oriented micromotors exploiting the chiral centers present on the bio-based ILs moiety.

\section{Experimental section}

\section{Materials}

$(S)-(-)-\beta$-Citronellol, (-)-myrtenol, and (-)-nopol were purchased from Sigma Aldrich. 1-Methylimidazole was obtained by Alfa Aesar. Phenylalanine and aqueous ammonia 

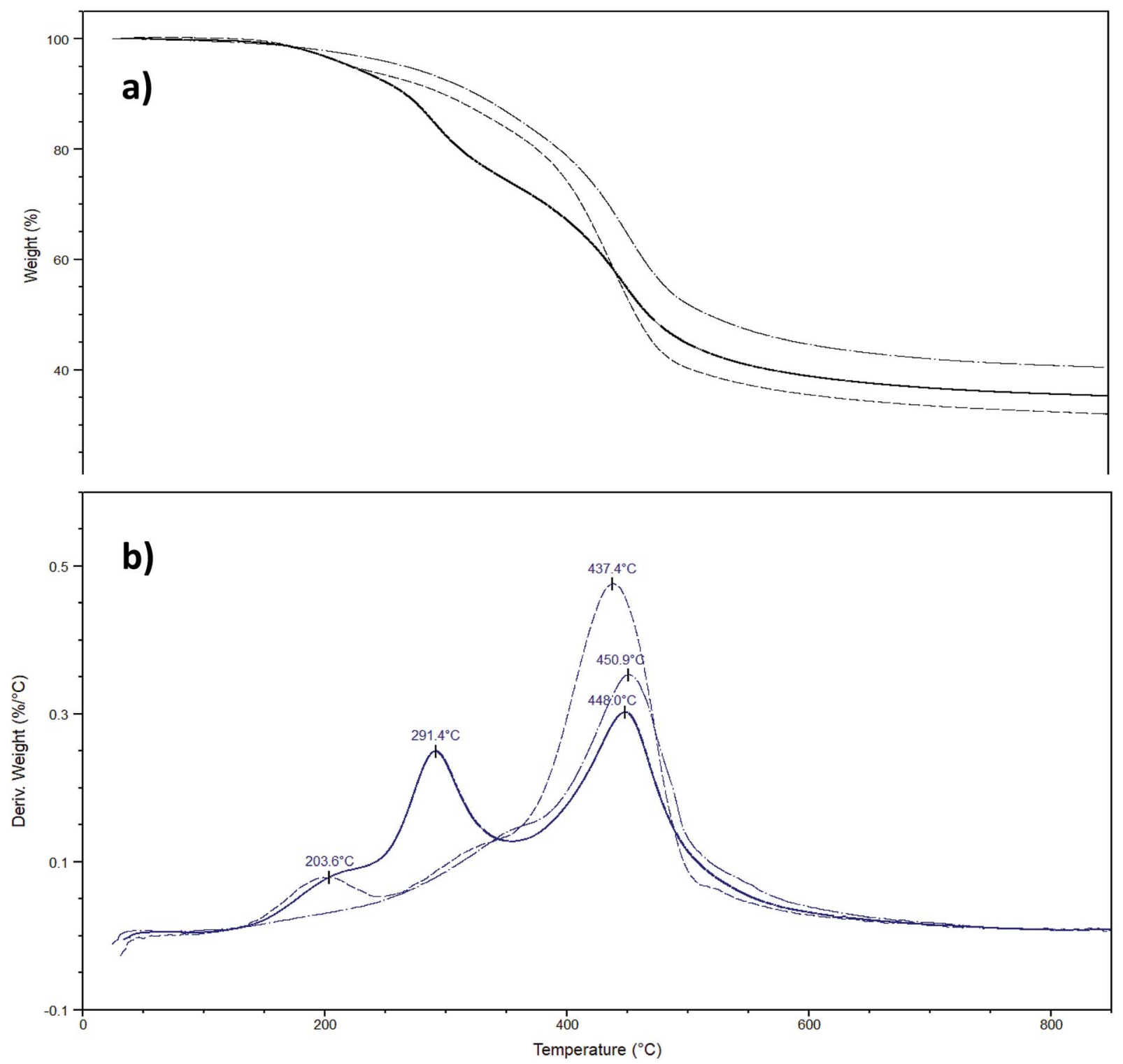

Fig. 5 a) Temperature-ramped TGA thermographs of CPS-SEC (dash dot line), IL functionalized sporopollenin $5 b$ (solid line) and IL functionalized sporopollenin $6 \mathrm{~b}$ (short dash line) with a heating rate of $10^{\circ} \mathrm{C} \mathrm{min}{ }^{-1}$. (b) Temperature-ramped TGA thermographs of CPS-SEC (dash dot line), IL functionalized sporopollenin $5 \mathrm{~b}$ (solid line) and IL functionalized sporopollenin $6 \mathrm{~b}$ (short dash line).

(33\%) were obtained from Fluka, whereas aqueous glyoxal (40\%) and aqueous formaldehyde (37\%) were purchased from Sigma Aldrich and Acros Organics, respectively. (3-Chloropropyl)triethoxysilane was obtained from Sigma Aldrich. Defatted pollen from Populus deltoides was purchased by Sigma Aldrich. All substances were used as received, without further purification, unless specified otherwise. All organic solvents were purchased from Sigma Aldrich and used without further purification.

\section{Methods}

TLC analysis were performed on aluminium-supported silica sheets (Merck TLC Silica gel 60 F254). The identification of the spots was carried out with an UV lamp (CAMAG, $\lambda=254 \mathrm{~nm}$ ) and/or by wetting the TLC with a $100 \mathrm{~g} \mathrm{~L}^{-1}$ ethanol solution of phosphomolybdic acid $\left(\mathrm{MoO}_{3} \cdot \mathrm{H}_{3} \mathrm{PO}_{4}\right)$ and heating it. Solution state NMR spectra were recorded on a Bruker Avance II 250 spectrometer at $250.13 \mathrm{MHz}\left({ }^{1} \mathrm{H}\right)$ and $52.90 \mathrm{MHz}\left({ }^{13} \mathrm{C}\right)$ using tetramethylsilane as internal standard. The following abbreviations are used: $\mathrm{s}=$ singlet, $\mathrm{d}=$ doublet, $\mathrm{dd}=$ double doublet, $\mathrm{t}$ $=$ triplet, $\mathrm{tt}=$ triplet of triplets, $\mathrm{td}=$ triplet of doublets, $\mathrm{qa}=$ quartet, qi $=$ quintuplet, $\mathrm{m}=$ multiplet. Solid state ${ }^{13} \mathrm{C}$ NMR spectra were collected at $126 \mathrm{MHz}$, using a Varian 500 spectrometer and high power ${ }^{1} \mathrm{H}$ "spinal" decoupling, for samples contained in $4 \mathrm{~mm}$ rotors spinning at $14 \mathrm{kHz}(\mathrm{CP})$ or at $8 \mathrm{kHz}$ (one pulse). A contact time of $2 \mathrm{~ms}$ was used for ${ }^{1} \mathrm{H}^{13}{ }^{13} \mathrm{C}$ crosspolarization ("tancpx" program). One pulse ${ }^{13} \mathrm{C}$ spectra were collected using a composite $\left(90^{\circ}-180^{\circ}-180^{\circ}\right)$ excitation pulse, "onepuldpth" with 16-phase cycling to suppress the Kel-F 
spacer signal adapted from ref. $49,4.2 \mu \mathrm{s}=90^{\circ}$ pulse, variable relaxation delay and shifts referenced to adamantane (38.5 and 29.4 ppm). ATR-FTIR spectra were recorded with an IR Cary 660 FTIR spectrometer (Agilent Technologies) using a macro-ATR accessory with a $\mathrm{Zn} / \mathrm{Se}$ crystal. The spectra were measured in a range from 4000 to $500 \mathrm{~cm}^{-1}$, with 32 scans both for background and samples. Chemical imaging data was collected by Agilent's ATR-imaging technique using a FTIR Cary 620 imaging system equipped with a $64 \times 64$ Focal Plane Array (FPA) detector cooled by liquid nitrogen. Spectra were measured, from 3300 to $900 \mathrm{~cm}^{-1}$, with 256 scans for both background and pollen samples. Thermal gravimetric analysis was performed on a TGA Q 500 (TA instruments), under nitrogen. For the sporopollenin-based materials: $\operatorname{ramp} 10.00{ }^{\circ} \mathrm{C} \min ^{-1}$ to $900.00{ }^{\circ} \mathrm{C}$, isothermal for $2.00 \mathrm{~min}$. Elemental analyses of the pristine and the IL-treated pollen were carried out on a Thermo Finnigan model Flash 1112 CHNS-O elemental analyzer at the RIAIDT of the University of Santiago de Compostela (USC, Spain). SEM images were acquired on sporopollenin and ILmodified sporopollenin using a Quanta FEG 450 SEM from FEI. Typical imaging conditions were: pressure $90 \mathrm{~Pa}$ (lowvacuum mode), accelerating voltage $15 \mathrm{kV}$, back scattered electrons detector. EDX analysis were performed with an XFlash 6|10 instrument from Bruker.

Synthesis of nopol mesylate (2a), citronellol mesylate (2b), and myrtenol chloride (2c). The $8.32 \mathrm{~g}$ (50.0 mmol) of (-)-nopol (1a) and $7.2 \mathrm{~mL}$ of $\mathrm{Et}_{3} \mathrm{~N}(51 \mathrm{mmol})$ were dissolved in $25 \mathrm{~mL}$ of $\mathrm{CH}_{2} \mathrm{Cl}_{2}$ in a $250 \mathrm{~mL}$ one-neck round-bottom flask. A solution of $4.0 \mathrm{~mL}$ of methansulfonyl chloride $(51 \mathrm{mmol})$ in $20 \mathrm{~mL}$ of $\mathrm{CH}_{2} \mathrm{Cl}_{2}$ was added under stirring at $0{ }^{\circ} \mathrm{C}$ within 30 minutes. The mixture was further stirred at room temperature until the TLC analysis $\left(\mathrm{CH}_{2} \mathrm{Cl}_{2}\right.$ : MeOH $\left.95: 5\right)$ demonstrated total consumption of alcohol. If the alcohol was still present after 24 hours, 0.2 equivalents of $\mathrm{Et}_{3} \mathrm{~N}$ and methansulfonyl chloride were added to the mixture. The reaction was quenched by adding $50 \mathrm{~mL}$ of a saturate solution of $\mathrm{NaHCO}_{3}$, and the aqueous phase was extracted three times with $20 \mathrm{~mL}$ of $\mathrm{CH}_{2} \mathrm{Cl}_{2}$. The collected organic phases were washed with $50 \mathrm{~mL}$ of milliQ water, and dried over $\mathrm{MgSO}_{4}$. After filtration, the solvent was removed under reduced pressure obtaining $12.11 \mathrm{~g}$ (49.6 mmol) of $(1 R, 5 S)$-2-(6,6-dimethylbicyclo[3.1.1] hept-2-en-2-yl)ethyl methanesulfonate (2a). Yield 99\%. TLC: $R_{\mathrm{f}}=0.88\left(\mathrm{SiO}_{2}, \mathrm{CH}_{2} \mathrm{Cl}_{2}\right.$ : MeOH 95 : 5).

${ }^{1} \mathrm{H}$ NMR (250.13 MHz, $\left.\mathrm{CDCl}_{3}\right) \delta(\mathrm{ppm}): 5.35(\mathrm{~s}, 1 \mathrm{H}), 4.18(\mathrm{t}$, $2 \mathrm{H}), 2.97(\mathrm{~s}, 3 \mathrm{H}), 2.37(\mathrm{~m}, 3 \mathrm{H}), 2.21(\mathrm{~s}, 2 \mathrm{H}), 2.03(\mathrm{~m}, 2 \mathrm{H}), 1.25(\mathrm{~s}$, $3 \mathrm{H}), 1.12(\mathrm{~d}, 1 \mathrm{H}), 0.81(\mathrm{~s}, 3 \mathrm{H})$.

${ }^{13} \mathrm{C} \mathrm{NMR}\left(52.90 \mathrm{MHz}, \mathrm{CDCl}_{3}\right) \delta(\mathrm{ppm}): 142.4,119.8,67.9,45.4$, 40.4, 37.9, 37.3, 36.2, 34.6, 31.2, 26.1, 21.0.

The synthesis of (3S)-3,7-dimethyloct-6-en-1-yl-methanesulfonate (2b) is analogous to that described for compound 2a. Yield $99 \%$.

TLC: $R_{\mathrm{f}}=0.88\left(\mathrm{SiO}_{2}, \mathrm{CH}_{2} \mathrm{Cl}_{2}: \mathrm{MeOH} 95: 5\right)$.

${ }^{1} \mathrm{H}$ NMR (250.13 MHz, $\left.\mathrm{CDCl}_{3}\right) \delta(\mathrm{ppm}): 5.03(\mathrm{tt}, 1 \mathrm{H}), 4.21(\mathrm{td}$, 2H), 2.95 (s, 3H), $1.94(\mathrm{~m}, 2 \mathrm{H}), 1.64(\mathrm{~s}, 3 \mathrm{H}), 1.56(\mathrm{~s}, 3 \mathrm{H}), 1.83-$ $1.08(\mathrm{~m}, 5 \mathrm{H}), 089$ (d, 3H).

${ }^{13} \mathrm{C} \mathrm{NMR}\left(52.90 \mathrm{MHz}, \mathrm{CDCl}_{3}\right) \delta(\mathrm{ppm}): 131.6,124.5,68.8,37.4$, 36.9, 29.1, 25.9, 25.4, 19.3, 18.8 .
The synthesis of $(1 R, 5 S)$-2-(chloromethyl)-6,6-dimethylbicyclo [3.1.1] hept-2-ene (3c) is analogous to that described for compound 2a. Yield $96 \%$.

TLC: $R_{\mathrm{f}}=0.89\left(\mathrm{SiO}_{2}, \mathrm{CH}_{2} \mathrm{Cl}_{2}: \mathrm{MeOH} 95: 5\right)$.

${ }^{1} \mathrm{H}$ NMR (250.13 MHz, $\left.\mathrm{CDCl}_{3}\right) \delta(\mathrm{ppm}): 5.59(\mathrm{~s}, 1 \mathrm{H}), 3.97(\mathrm{~s}$, $2 \mathrm{H}), 2.41(\mathrm{~m}, 1 \mathrm{H}), 2.26(\mathrm{~m}, 3 \mathrm{H}), 2.08(\mathrm{~m}, 1 \mathrm{H}), 1.29(\mathrm{~s}, 3 \mathrm{H}), 1.17$ (d, 1H), $082(\mathrm{~s}, 3 \mathrm{H})$.

${ }^{13} \mathrm{C} \mathrm{NMR}\left(52.90 \mathrm{MHz}, \mathrm{CDCl}_{3}\right) \delta(\mathrm{ppm}): 144.4,122.7,48.9,44.5$, 40.7, 38.3, 31.9, 31.6, 26.3, 21.4.

Synthesis of nopol (4a), citronellol (4b), and myrtenol (4c) imidazole. A $250 \mathrm{~mL}$ three-neck round-bottom flask was equipped with a vacuum adapter and connected to the argon line. After flushing argon for a minute, $3.27 \mathrm{~g}$ of a $60 \%(\mathrm{w} / \mathrm{w})$ $\mathrm{NaH}$ oil suspension $(81.6 \mathrm{mmol}$ of $\mathrm{NaH}$ ) were added to the flask and washed three times with $20 \mathrm{~mL}$ of hexane, which was removed with a Pasteur pipette after one minute of gentle stirring. At this stage, THF $(10 \mathrm{~mL})$ was added, and the flask was equipped with two addition funnels containing $2.79 \mathrm{~g}$ (41.0 $\mathrm{mmol})$ of imidazole in $20 \mathrm{~mL}$ of THF and $5.02 \mathrm{~g}(20.6 \mathrm{mmol})$ of $3 \mathbf{a}$ in $20 \mathrm{~mL}$ of THF, respectively. The imidazole solution was carefully added dropwise at $0{ }^{\circ} \mathrm{C}$, to avoid excessive effervescence. After stirring for 10 minutes, the mesylate solution was added slowly at $0{ }^{\circ} \mathrm{C}$ over 15 minutes, and the mixture was allowed to warm up to room temperature and further stirred for 24 hours. As the TLC showed the presence of 3a, the temperature was raised to $50{ }^{\circ} \mathrm{C}$, and the reaction was continued until total conversion of the mesylate precursor was observed. The reaction was quenched by slowly adding water to the mixture, until no more hydrogen gas evolved. The solvent was evaporated under reduced pressure. $50 \mathrm{~mL}$ of water and $50 \mathrm{~mL}$ of $\mathrm{CH}_{2} \mathrm{Cl}_{2}$ were added, and the aqueous phase was further extracted with two portions of $\mathrm{CH}_{2} \mathrm{Cl}_{2}(50 \mathrm{~mL})$. The merged organic phases were washed with $100 \mathrm{~mL} \mathrm{H}_{2} \mathrm{O}$, and dried over $\mathrm{MgSO}_{4}$. After filtration, evaporation of the solvent, and flash chromatography purification $\left(\mathrm{CH}_{2} \mathrm{Cl}_{2}: \mathrm{MeOH} 95: 5\right), 3.42 \mathrm{~g}$ (15.8 mmol) of a light yellow liquid was obtained. Yield $87 \%$. $[\alpha]_{\mathrm{D}}^{20}-21.6$ (c 1.1, $\left.\mathrm{CHCl}_{3}\right)$.

TLC: $R_{\mathrm{f}}=0.35\left(\mathrm{SiO}_{2}, \mathrm{CH}_{2} \mathrm{Cl}_{2}: \mathrm{MeOH} 95: 5\right)$.

${ }^{1} \mathrm{H}$ NMR (250.13 MHz, $\left.\mathrm{CDCl}_{3}\right) \delta(\mathrm{ppm}): 7.38(\mathrm{~s}, 1 \mathrm{H}), 6.96(\mathrm{~s}$, $1 \mathrm{H}), 6.84(\mathrm{~s}, 1 \mathrm{H}), 5.20(\mathrm{~m}, 1 \mathrm{H}), 3.88(\mathrm{t}, 2 \mathrm{H}), 2.34(\mathrm{~m}, 3 \mathrm{H}), 2.14(\mathrm{~m}$, $2 \mathrm{H}), 1.98(\mathrm{~m}, 2 \mathrm{H}), 1.22(\mathrm{~s}, 3 \mathrm{H}), 1.06(\mathrm{~d}, 1 \mathrm{H}), 0.75(\mathrm{~s}, 3 \mathrm{H})$.

${ }^{13} \mathrm{C}$ NMR $\left(52.90 \mathrm{MHz}, \mathrm{CDCl}_{3}\right) \delta(\mathrm{ppm}): 143.7,137.0,129.2$, 119.3, 118.7, 45.5, 45.2, 40.6, 38.4, 38.0, 31.6, 31.2, 26.2, 21.1.

The synthesis of 1-[(3S)-3,7-dimethyloct-6-en-1-yl]-imidazole (4b) is analogous to that described for compound 4a. Yield 94\%. $[\alpha]_{\mathrm{D}}^{20}-2.7\left(\mathrm{c} 0.9, \mathrm{CHCl}_{3}\right)$.

TLC: $R_{\mathrm{f}}=0.43\left(\mathrm{SiO}_{2}, \mathrm{CH}_{2} \mathrm{Cl}_{2}: \mathrm{MeOH} 95: 5\right)$.

${ }^{1} \mathrm{H}$ NMR (250.13 MHz, $\left.\mathrm{CDCl}_{3}\right) \delta(\mathrm{ppm}): 7.40(\mathrm{~s}, 1 \mathrm{H}), 6.99(\mathrm{~s}$, $1 \mathrm{H}), 6.85(\mathrm{~s}, 1 \mathrm{H}), 5.01(\mathrm{t}, 1 \mathrm{H}), 3.90(\mathrm{~m}, 2 \mathrm{H}), 1.63(\mathrm{~s}, 3 \mathrm{H}), 1.54(\mathrm{~s}$, $3 \mathrm{H}), 2.00-1.00(\mathrm{~m}, 7 \mathrm{H}), 0.89(\mathrm{~s}, 3 \mathrm{H})$.

${ }^{13} \mathrm{C}$ NMR (52.90 MHz, $\left.\mathrm{CDCl}_{3}\right) \delta(\mathrm{ppm}):$ 137.2, 131.8, 129.5, 124.4, 118.9, 45.2, 38.3, 36.9, 29.9, 25.9, 25.5, 19.4, 17.8 .

The synthesis of $1-\{[(1 R, 5 S)-6,6$-dimethylbicyclo[3.1.1]hept-2en-2-yl]methyl\}-imidazole (4c) is analogous to that described for compound 4a. Yield 76\%. $[\alpha]_{\mathrm{D}}^{20}-29.0$ (c 1.4, $\mathrm{CHCl}_{3}$ ).

TLC: $R_{\mathrm{f}}=0.43\left(\mathrm{SiO}_{2}, \mathrm{CH}_{2} \mathrm{Cl}_{2}: \mathrm{MeOH} 95: 5\right)$. 
${ }^{1} \mathrm{H}$ NMR (250.13 MHz, $\left.\mathrm{CDCl}_{3}\right) \delta(\mathrm{ppm}): 7.40(\mathrm{~s}, 1 \mathrm{H}), 6.99(\mathrm{~s}$, $1 \mathrm{H}), 6.83(\mathrm{~s}, 1 \mathrm{H}), 5.43(\mathrm{~s}, 1 \mathrm{H}), 4.36(\mathrm{~s}, 2 \mathrm{H}), 2.50-1.80(\mathrm{~m}, 5 \mathrm{H})$, $1.19(\mathrm{~s}, 3 \mathrm{H}), 1.09(\mathrm{~d}, 1 \mathrm{H}), 0.72(\mathrm{~s}, 3 \mathrm{H})$.

${ }^{13} \mathrm{C}$ NMR (52.90 MHz, $\mathrm{CDCl}_{3}$ ) $\delta(\mathrm{ppm}): 143.2,137.2,139.1$, 121.3, 119.2, 51.9, 43.4, 40.4, 37.9, 31.6, 31.1, 25.9, 20.9.

Synthesis of methyl (2S)-2-(imidazol-1-yl)-3-phenylpropanoateimidazole (4d). $4.05 \mathrm{~g}(49.9 \mathrm{mmol})$ of $37 \%(\mathrm{w} / \mathrm{w})$ formaldehyde aqueous solution and $7.22 \mathrm{~g}(49.7 \mathrm{mmol})$ of glyoxal $40 \%(\mathrm{w} / \mathrm{w})$ aqueous solution were introduced into a $100 \mathrm{~mL}$ two-neck round-bottom flask. The latter was equipped with a condenser and an addition funnel containing a solution composed of $8.26 \mathrm{~g}(50.0 \mathrm{mmol})$ of phenylalanine, $2.02 \mathrm{~g}(50.6 \mathrm{mmol})$ of $\mathrm{NaOH}, 2.90 \mathrm{~mL}(56.2 \mathrm{mmol})$ of $33 \%(\mathrm{w} / \mathrm{w}) \mathrm{NH}_{3}$ aqueous solution, and $30 \mathrm{~mL}$ of milliQ water. After heating the flask at $50{ }^{\circ} \mathrm{C}$, the solution was added over 30 minutes, and the resulting mixture was further stirred for 4 hours, always maintaining the temperature at $50{ }^{\circ} \mathrm{C}$. The brown solution was transferred into a $250 \mathrm{~mL}$ round-bottom flask, and the solvent was evaporated under reduced pressure. The resulting solid was dissolved in $100 \mathrm{~mL}(2.47 \mathrm{~mol})$, and $7.3 \mathrm{~mL}(101 \mathrm{mmol})$ of $\mathrm{SOCl}_{2}$ were added at $0{ }^{\circ} \mathrm{C}$ within 10 minutes. The mixture was refluxed for 24 hours, while periodically checking its progress by TLC analysis (EtOAc). The solvent was then evaporated under vacuum, and the excess $\mathrm{SOCl}_{2}$ was removed by redissolving the dark solid in $50 \mathrm{~mL} \mathrm{MeOH}$ and applying a vacuum. This operation was repeated twice. The crude solid was purified by flash chromatography (EtOAC), affording $5.31 \mathrm{~g}(23.0 \mathrm{mmol})$ of a brown viscous liquid. Yield $46 \%$. $[\alpha]_{\mathrm{D}}^{20}=-59.0(\mathrm{c}=1.1$, methanol), in agreement with literature. ${ }^{50}$

TLC: $R_{\mathrm{f}}=0.31\left(\mathrm{SiO}_{2}\right.$, EtOAc).

${ }^{1} \mathrm{H}$ NMR (250.13 MHz, $\left.\mathrm{CDCl}_{3}\right) \delta(\mathrm{ppm}): 7.35(\mathrm{~s}, 1 \mathrm{H}), 7.17(\mathrm{~m}$, 2H), $7.00(\mathrm{~s}, 2 \mathrm{H}), 6.95(\mathrm{~m}, 2 \mathrm{H}), 4.85(\mathrm{dd}, 1 \mathrm{H}), 3.70(\mathrm{~s}, 3 \mathrm{H}), 3.41$ (dd, 1H), 3.16 (dd, 1H), $1.22(\mathrm{~s}, 3 \mathrm{H}), 1.06(\mathrm{~d}, 1 \mathrm{H}), 0.75(\mathrm{~s}, 3 \mathrm{H})$.

${ }^{13} \mathrm{C}$ NMR $\left(52.90 \mathrm{MHz}, \mathrm{CDCl}_{3}\right) \delta(\mathrm{ppm}): 169.41,136.75,135.09$, 129.29, 128.59, 128.50, 127.22, 117.86, 61.21, 57.20, 39.39.

Synthesis of 4-(3-methylimidazolium-1-yl)butane-1-sulfonate. $19.8 \mathrm{~g}$ (241 mmol) of methylimidazole and $30.0 \mathrm{~g}(220$ $\mathrm{mmol}$ ) of 1,4-butane sultone were introduced into a $500 \mathrm{~mL}$ one-neck round-bottom flask, along with $200 \mathrm{~mL}$ of MeCN. The flask was equipped with a condenser, and the solution was stirred at $90{ }^{\circ} \mathrm{C}$ for 48 hours. The milky mixture obtained was filtered on a Buchner funnel, and the white powder on the filter was washed with cold MeCN and dried under vacuum, recovering $45.2 \mathrm{~g}$ ( $207 \mathrm{mmol}$ ) of a white powder. Yield 94\%. Then, an equimolar amount of concentrated $\mathrm{H}_{2} \mathrm{SO}_{4}$ was carefully added dropwise at $0{ }^{\circ} \mathrm{C}$, and the mixture was stirred at room temperature for 1 hour. The solvent was evaporated under reduced pressure, obtaining the uncoloured viscous ionic liquid $\left[\mathrm{HSO}_{3} \mathrm{C}_{4} \mathrm{mim}\right]\left[\mathrm{HSO}_{4}\right]$.

${ }^{1} \mathrm{H}$ NMR (250.13 MHz, CD $\mathrm{CD}_{3} \mathrm{O}(\mathrm{ppm}): 9.01(\mathrm{~s}, 1 \mathrm{H}), 7.70(\mathrm{t}$, $1 \mathrm{H}), 7.61(\mathrm{t}, 1 \mathrm{H}), 4.30(\mathrm{t}, 2 \mathrm{H}), 3.79(\mathrm{~s}, 3 \mathrm{H}), 2.88(\mathrm{t}, 2 \mathrm{H}), 2.09$ (qi, $2 \mathrm{H}), 1.81$ (qi, 2H).

${ }^{13} \mathrm{C}$ NMR (52.90 MHz, $\left.\mathrm{CD}_{3} \mathrm{OD}\right) \delta(\mathrm{ppm}): 138.8,125.7,124.5$, 52.3, 51.0, 37.3, 30.7, 23.6.

Extraction of sporopollenin exine capsules (SEC) from Populus deltoides pollen. $2.50 \mathrm{~g}$ of defatted Populus deltoides pollen were added to the $\left[\mathrm{HSO}_{3} \mathrm{C}_{4} \mathrm{mim}\right]\left[\mathrm{HSO}_{4}\right]$ ionic liquid and the mixture was heated to $160{ }^{\circ} \mathrm{C}$ for 80 minutes under continuous stirring. The reaction was quenched by adding $100 \mathrm{~mL}$ of milliQ water. The suspension was filtered on a Buchner funnel, and the black solid was washed with milliQ water and then with methanol. For each solvent, the washing was continued until the filtrate was colourless. The black/brown powder was dried at $60{ }^{\circ} \mathrm{C}$ overnight, obtaining $0.46 \mathrm{~g}$ of sporopollenin.

Synthesis of the 3-chloropropyl-functionalized SEC (CPSSEC). In a $50 \mathrm{~mL}$ one-neck round-bottom flask, $0.46 \mathrm{~g}$ of sporopollenin were suspended in $20 \mathrm{~mL}$ of toluene, and $1.85 \mathrm{~mL}$ (7.68 mmol) of (3-chloropropyl)triethoxysilane were added. The suspension was refluxed for 48 hours under continuous stirring. At the end of the reaction, the solid $(0.51 \mathrm{mg})$ was recovered by filtration on Buchner funnel, washed with toluene and then with methanol, and dried at $60{ }^{\circ} \mathrm{C}$ overnight.

Synthesis of SEC-supported ILs (5a-d). In a $50 \mathrm{~mL}$ one-neck round-bottom flask, $0.100 \mathrm{~g}$ of sporopollenin were suspended in $10 \mathrm{~mL}$ of toluene containing $1.5 \mathrm{mmol}$ of 1-alkylimidazole (4ad). The suspension was stirred under reflux condition for 48 hours. At the end of the reaction, the solid $(0.120 \mathrm{mg})$ was recovered by filtration on Buchner funnel, washed with toluene and then with methanol, and dried at $60{ }^{\circ} \mathrm{C}$ overnight.

Synthesis of hydrophobic ILs-modified SEC (6b, 6d). $20 \mathrm{mg}$ of SEC-supported ILs (5b and 5d) were suspended in $0.5 \mathrm{~mL}$ of milliQ water containing $0.100 \mathrm{~g}(0.35 \mathrm{mmol})$ of $\operatorname{LiTf}_{2} \mathrm{~N}$ and stirred at room temperature for 48 hours. The solid ( $22 \mathrm{mg}$ ) was recovered by filtration and dried at $60{ }^{\circ} \mathrm{C}$ overnight.

\section{Conflicts of interest}

There are no conflicts to declare.

\section{Acknowledgements}

We thank UNIPI for the financial support.

\section{References}

1 P. J. Hallet and T. Welton, Chem. Rev., 2011, 111, 3508.

2 C. Chiappe and D. Pieraccini, J. Phys. Org. Chem., 2005, 18, 275.

3 R. P. Swatloski, S. K. Spear, J. D. Holbrey and R. D. Rogers, J. Am. Chem. Soc., 2002, 124, 4974.

4 A. Mezzetta, L. Guazzelli and C. Chiappe, Green Chem., 2017, 19, 1235.

5 C. Dai, J. Zhang, C. Huang and Z. Lei, Chem. Rev., 2017, 117, 6929.

6 C. Chiappe and C. S. Pomelli, Eur. J. Org. Chem., 2014, 28, 6120.

7 C. Chiappe and C. S. Pomelli, Ionic liquids and green Chemistry, in Analytical application of ionic liquids, ed. M. Koehl, World Scientific, New Jersey, 2016.

8 S. P. F. Costa, A. M. O. Azevedo, P. C. A. G. Pinto and M. L. M. F. S. Saraiva, ChemSusChem, 2017, 10, 2321.

9 J. Hulsbosch, D. E. De Vos, K. Binnemans and R. Ameloot, ACS Sustainable Chem. Eng., 2016, 4, 2917. 
10 A. Mezzetta, L. Guazzelli, M. Seggiani, C. S. Pomelli, M. Puccini and C. Chiappe, Green Chem., 2017, 19, 3103.

11 Supported Ionic Liquids: Fundamentals and Applications, ed. R. Fehrmann, A. Riisager and M. Haumann, Wiley-VCH Verlag GmbH \& Co. KGaA, 2014.

12 B. Xin and J. Hao, Chem. Soc. Rev., 2014, 43, 7171.

13 S. Wilmesmeier and R. Wiermann, J. Plant Physiol., 1995, 146, 22.

14 G. Shaw, in Sporopollenin, Academic Press, London, New York, 1971, pp. 305-348.

15 E. Domínguez, J. A. Mercado, M. A. Quesada and A. Heredia, Sex. Plant Reprod., 1999, 12, 171.

16 H. Bubert, J. Lambert, S. Steuernagel, F. Ahlers and R. Wiermann, Z. Naturforsch. C Bio. Sci., 2002, 57, 1035.

17 K. Wehling, C. Niester, J. J. Boon, M. T. M. Willemse and R. Wiermann, Planta, 1989, 179, 376.

18 J. Brooks and G. Shaw, Chem. Geol., 1972, 10, 69.

19 S. Barrier, A. Loebbert, A. J. Boasman, A. N. Boa, M. Lorch, S. L. Atkin and G. MacKenzie, Green Chem., 2010, 12, 234.

20 F. A. Loewus, B. G. Baldi, V. R. Franceschi, L. D. Meinert and J. J. McCollum, Plant Physiol., 1985, 78, 652.

21 E. Domínguez, A. Heredia, J. A. Mercado and M. A. Quesada, Grana, 1998, 37, 93.

22 S. Barrier, A. S. Rigby, A. Diego-Taboada, M. J. Thomasson, G. Mackenzie and S. L. Atkin, LWT-Food Sci. Technol., 2010, 43, 73 .

23 A. Berthod, M. J. Ruiz-Angel and S. Huguet, Anal. Chem., 2005, 77, 4071.

24 S. Barrier, A. Diego-Taboada, M. J. Thomasson, L. Madden, J. C. Pointon, J. D. Wadhawan, S. T. Beckett, S. L. Atkin and G. Mackenzie, J. Mater. Chem., 2011, 21, 975.

25 S. U. Atwe, Y. Ma and H. S. Gill, J. Controlled Release, 2014, 194, 45.

26 M. G. Potroz, R. C. Mundargi, J. J. Gillissen, E. L. Tan, S. Meker, J. H. Park, H. Jung, S. Park, D. Cho, S. I. Bang and N. J. Cho, Adv. Funct. Mater., 2017, 27, 1.

27 E. Maltas, I. H. Gubbuk and S. Yildiz, Biochem Biophys Rep, 2017, 7, 201.

28 A. Cimen, A. Bilgic, A. N. Kursunlu, I. H. Gubbuk and H. I. Ucan, Desalin. Water Treat., 2014, 52, 4837.

29 E. Pehlivan, U. S. Vural, A. Ayar and S. Yildiz, Sep. Sci. Technol., 1996, 31, 1643.
30 G. Mackenzie and G. Shaw, Int. J. Pept. Protein Res., 1980, 15, 298.

31 E. Yilmaz, M. Sezgin and M. Yilmaz, J. Mol. Catal. B: Enzym., 2011, 69, 35.

32 H. Tutar, E. Yilmaz, E. Pehlivan and M. Yilmaz, Int. J. Biol. Macromol., 2009, 45, 315.

33 M. Keles, Synth. React. Inorg., Met.-Org., Nano-Met. Chem., 2013, 43, 575.

34 T. Baran, I. Sargin, M. Kaya, A. Menteş and T. Ceter, J. Colloid Interface Sci., 2017, 486, 194.

35 S. M. Alshehri, H. A. Al-Lohedan, E. Al-Farraj, N. Alhokbany, A. A. Chaudhary and T. Ahamad, Int. J. Pharm., 2016, 504, 39.

36 S. M. Alshehri, H. A. Al-Lohedan, A. A. Chaudhary, E. AlFarraj, N. Alhokbany, Z. Issa, S. Alhousine and T. Ahamad, Eur. J. Pharm. Sci., 2016, 88, 158.

37 Y. Wang, T. Len, Y. Huang, A. Diego Taboada, A. N. Boa, C. Ceballos, F. Delbecq, G. Mackenzie and C. Len, ACS Sustainable Chem. Eng., 2017, 5, 392.

38 G. Erdtman, Sven. Bot. Tidskr., 1960, 54, 561.

39 F. A. Loewus, B. G. Baldi, V. R. Franceschi, L. D. Meinert and J. J. McCollum, Plant Physiol., 1985, 78, 652.

40 E. Domínguez, A. Heredia, J. A. Mercado and M. A. Quesada, Grana, 1998, 37, 93.

41 F. Zetzsche and K. Huggler, Liebigs Ann., 1928, 461, 89.

42 R. C. Mundargi, M. G. Potroz, J. H. Park, J. Seo, E.-L. Tan, J. H. Lee and N.-J. Cho, Sci. Rep., 2016, 6, 19960.

43 C. Chiappe, G. C. Demontis, V. Di Bussolo, M. J. Rodriguez Douton, F. Rossella, C. S. Pomelli, S. Sartini and S. Caporali, Green Chem., 2017, 19, 1028.

44 T. Baran, I. Sargin, M. Kaya, A. Menteş and T. Ceter, J. Colloid Interface Sci., 2017, 486, 194.

45 W. Bao, Z. Wang and Y. Li, J. Org. Chem., 2003, 68, 591.

46 C. Descolas-Gros and C. Scholzel, New Phytol., 2007, 176, 390.

47 B. P. Binks, A. N. Boa, M. A. Kibble, G. Mackenzie and A. Rochera, Soft Matter, 2011, 7, 4017.

48 H. Wong, M. G. Potroz, J. A. Jackman, B. Khezri, T. Maric, N.-J. Cho and M. Pumera, Adv. Funct. Mater., 2017, 27, 1702338.

49 M. R. Bendall and R. E. Gordon, Magn. Reson. Med., 1985, 2, 91.

50 A. Meyer, M. A. Taige, T. Strassner and E. Gordon, J. Organomet. Chem., 2009, 694, 1861. 